\title{
Dengue no Distrito Federal, e os desafios em meio à pandemia
}

\author{
Dengue fever in the Federal District, and the challenges in the midst of the pandemic \\ Dengue em el Distrito Federal, y los desafíos em medio de la pandemia
}

Renato Kennedy Souza Araújo ORCID: https://orcid.org/0000-0001-8770-7911 Faculdade LS - FACELS, Brasil E-mail: Renatok66@gmail.com

Valéria Cristina de Araújo Frota ORCID: https://orcid.org/0000-0002-0956-9194 Faculdade LS - FACELS, Brasil

E-mail: valeria.frota04@1seducacional.com

Larissa Lorrane Silva de Oliveira ORCID: https://orcid.org/0000-0002-7139-8963 Faculdade LS - FACELS, Brasil

E-mail: larissa.oliveira71@1seducacional.com

Vitoria Aparecida de Souza e Silva ORCID: https://orcid.org/0000-0002-4381-2514 Faculdade LS - FACELS, Brasil

E-mail: vitoria.silva50@1seducacional.com

Luiza Gabrielle Silva da Costa ORCID: https://orcid.org/0000-0001-7829-7316 Faculdade LS - FACELS, Brasil

E-mail: luiza.costa04@1seducacional.com

Geisiele Elienay Praga Mota ORCID: https://orcid.org/0000-0002-3959-2539 Faculdade LS - FACELS, Brasil

E-mail: geisiele.mota85@1seducacional.com

Gabriela Moreira de Souza ORCID: https://orcid.org/0000-0002-0500-0400 Faculdade LS - FACELS, Brasil

E-mail: gabriela.sousa60@1seducacioinal.com

Amanda Dourado de Lucena ORCID: https://orcid.org/0000-0002-9800-3490 Faculdade LS - FACELS, Brasil E-mail: Amanda.lucena55@1seducacional.com

Adriano Rios da Silva

ORCID: https://orcid.org/0000-0001-5462-7632 Universidade de Brasília, Brasil E-mail: adriano.silva@1s.edu.br

Krain Santos de Melo

ORCID: https://orcid.org/0000-0002-6237-4505 Universidade de Brasília, Brasil E-mail: krain.melo@1s.edu.br

Nara Rúbia Souza

ORCID: https://orcid.org/0000-0002-9308-8608 Universidade de Brasília, Brasil E-mail: nara.souza@1s.edu.br

\section{Resumo}

Situado na Região Centro-Oeste, o Distrito Federal é a menor unidadefederativa brasileira e a única que não tem municípios, sendo dividida em 33 regiões administrativas, totalizando uma área de $5779,999 \mathrm{~km}^{2}$. A disseminação do vetor é ampla entre latitudes $35^{\circ} \mathrm{N}$ e $35^{\mathrm{a}} \mathrm{S}$, consideradas zonas intertropicais, se tratando do Aedes aegypty. O presente trabalho tem como objetivo revisar fatores determinantes à reprodução, transmissão e prevalência, assim como medidas de prevenção e sua eficiência junto com as políticas públicas e participação da população no auxílio no mapeamento preciso com relação a espaços-temporais nas regiões administrativas do Distrito Federal, riscos potenciais a população, situação do quadro sorotipos dos vírus, antes e durante a pandemia. A pesquisa foi realizada no Distrito Federal com dados referentes ao período de 2015 a 2020. Os dados foram obtidos pela Secretaria de Vigilância à Saúde, Secretaria de Saúde do Distrito Federal, boletins epidemiológicos e artigos atuais sobre Dengue e Dengue relacionada a Covid-19nas plataformas de pesquisa científica. A colaboração da sociedade, profissionais 
dasaúde e representantes governamentais são a força no enfrentamento à Covid-19, causado pelo vírus Sars-cov 2, assim como à Dengue com seus sorotipos. Assim, é necessário demandar a devida importância às duas patologias de forma responsávele comprometida, priorizando a saúde pública de modo a evitar um descontrole problemático tanto pelo Covid-19 e as arboviroses, visto a complexidade de ambas, e suas dependências de processos de organização urbana, social e governamental em seu controle.

Palavras-chave: Aedes aegypti; Dengue; Pandemia; COVID-19.

\begin{abstract}
Located in the Midwest Region, the Federal District is the smallest Brazilian federative unit and the only one that has no municipalities, being divided into 33 administrative regions, totaling an area of 5,779,999 $\mathrm{km}^{2}$. The spread of the vector is wide between latitudes $35^{\circ} \mathrm{N}$ and $35^{\mathrm{a}} \mathrm{S}$, considered intertropical zones, in the case of Aedes aegypty. The present work aims to review factors determining reproduction, transmission and prevalence, as well as preventive measures and their efficiency together with public policies and participation of the population in helping to accurately map space-time in the administrative regions of the Federal District, potential risks to the population, status of virus serotypes, before and during the pandemic. The research was carried out in the Federal District with data referring to the period from 2015 to 2020. The data were obtained by the Department of Health Surveillance, Department of Health of the Federal District, epidemiological bulletins and current articles on Dengue and Dengue related to Covid-19 in scientific research platforms. The collaboration of society, health professionals and government representatives are the strength in combating covid-19, caused by the Sars-cov 2 virus, as well as Dengue with its serotypes. Thus, it is necessary to demand due importance to the two pathologies in a responsible and committed way, prioritizing public health in order to avoid a problematic lack of control by both Covid-19 and arboviruses, given the complexity of both, and their dependence on organizational processes. urban, social and governmental control.
\end{abstract}

Keywords: Aedes aegypti; Dengue; Pandemic; COVID-19.

\title{
Resumen
}

Situado en la Región Centro-Oeste, el Distrito Federal es la menor unidad federativa brasileña y la única sin municipios, estando dividido en 33 regiones administrativas, que suman una superficie de 5779,999 km². La difusión del vector es amplia entre las latitudes $35^{\circ} \mathrm{N}$ y $35^{\mathrm{a}} \mathrm{S}$, consideradas zonas intertropicales, en el caso de Aedes aegypty. El presente trabajo tiene como objetivo revisar los factores que determinan la reproducción, la transmisión y la prevalencia, así como las medidas de prevención y su eficacia junto con las políticas públicas y la participación de la población en la ayuda en el mapeo preciso con respecto al espacio-tiempo en las regiones administrativas del Distrito Federal, los riesgos potenciales para la población, la situación de los serotipos del virus, antes y durante la pandemia. La investigación se realizó en el Distrito Federal con datos referidos al periodo de 2015 a 2020. Los datos fueron obtenidos por la Secretaría de Vigilancia de la Salud, Secretaría de Salud del Distrito Federal, boletines epidemiológicos y artículos actuales sobre Dengue y Dengues relacionadas con Covid-19 en plataformas de investigación científica. La colaboración de la sociedad, los profesionales de la salud y los representantes del gobierno son la fuerza en la lucha contra el Covid-19, causado por el virus Sars-cov 2, así como el Dengue y sus serotipos. Así, es necesario exigir la debida importancia a ambas patologías de forma responsable y comprometida, priorizando la salud pública para evitar una problemática incontrolada tanto por Covid-19 como por arboviros, dada la complejidad de ambas, y su dependencia de los procesos de organización urbana, social y gubernamental en su control.

Palabras clave: Aedes aegypti; Dengue; Pandemia; COVID-19

\section{Introdução}

A dengue é uma doença febril aguda, de etiologia viral e de evoluçãobenigna na forma clássica, e grave quando se apresenta na forma hemorrágica. A dengue é, hoje, a mais importante arbovirose (doença transmitida por artrópodes) que afeta o homem e constitui-se em sério problema de saúde pública no mundo, especialmente nos países tropicais, onde as condições do meio ambiente favorecemo desenvolvimento e a proliferação do Aedes aegypti, principal mosquito vetor (Valle et al., 2015).

Ela pode ser desenvolvida em quatro sorotipos, a dengue tipo 1, 2, 3 e 4. Ainfecção por dengue causa uma doença cujo espectro inclui desde infecçõesinaparentes até quadros de hemorragia e choque, podendo evoluir para o êxito letal. Por ser uma doença de notificação compulsória, todo caso suspeito deve sercomunicado, pela via mais rápida, ao Serviço de Vigilância Epidemiológica maispróximo. Medidas de Controle A notificação dos casos suspeitos, a investigação dolocal 
provável de infecção, bem como a busca ativa de casos são medidasimportantes. A única garantia para que não exista a dengue é a ausência do vetor (Valle et al., 2015).

De acordo com Santos (2020), 'devido a pandemia causada pelo coronavírus, a mídia e as redes sociais estão dando prioridade ao Covid-19, as medidas de prevenção e controle dessa patologia.' Na situação atual em que o Brasilvive, meios de comunicações, ações dos profissionais de saúde, estão voltadas para combate do Covid-19. Enquanto isso a dengue atingiu números alarmantes, dando um aumento de 22,7\% comparado com o boletim de 2019. Existe um descontrole problemático tanto pelo Covid-19 e as arboviroses, pois não existe vacina e nem drogas específicas.

É necessário promover, exaustivamente, a Educação em Saúde até que a comunidade adquira conhecimentos e consciência do problema para que possa participar efetivamente. Este artigo tem como objetivo fazer uma revisão dos fatores determinantes deste vírus, situação do quadro de sorotipos do vírus, e analisar a distribuição da dengue no Distrito Federal antes e durante a pandemia, junto com as medidas governamentais e participação da população.

\section{Metodologia}

A pesquisa foi realizada no Distrito Federal que é uma das 27 unidades federativas do Brasil. Situado na Região Centro-Oeste, é a menor unidade federativa brasileira e a única que não tem municípios, sendo dividida em 33 regiões administrativas, totalizando uma área de $5779,999 \mathrm{~km}^{2}$. Segundo o Instituto Brasileiro de Geografia e Estatística (IBGE), sua população foi estimada em 2.974 .703 habitantes para o ano de 2020. Trata-se de um estudo epidemiológico descritivo, Explicativo (De Oliveira, 2011) realizado com dados referentes ao período de 2015 a 2020. Os dados foram obtidos pela Secretaria de Vigilância à Saúde, Secretaria de Saúde do Distrito Federal por meio de seus boletins epidemiológicos e artigos atuais sobre Dengue e Dengue relacionada a Covid-19 nas plataformas de pesquisa científica, Scientific Eletronic Library Online (SciElo), Literatura Latino-Americana e do Caribe em Ciências da Saúde (Lilacs) e Google acadêmico, onde os critérios foram o ano, impacto do estudo e a pertinência sobre o tema.

\section{Resultados e Discussão}

De acordo com o boletim Epidemiológico entre as Semanas Epidemiológicas (29/12/2019 a 07/11/2020) em 2020 foram notificados 46.145 casos prováveis de dengue (taxa de incidência de casos por 100 mil habitantes), de residentes do Distrito Federal. No ano de 2020 houve um aumento de 22,7\% no número de casos prováveis, quando comparado ao mesmo período de 2019 em que foram registrados 37.613 casos prováveis. Os subtipos circulantes da dengue no DF são o DenV-1, detectado em 384 amostras, e o DenV-2, presente em apenas 32 do total deamostras analisadas pelo Laboratório Central de Saúde do Distrito Federal - LACENDF. O DenV-2, predominou no ano de 2019, sendo detectado em 71,1\%, e o DenV-1, em $28,9 \%$ do total de amostras analisadas.

As regiões de saúde do Distrito Federal estão com alta incidência, estando uma região administrativa com média incidência que são o Sudoeste, Octogonal e 30 regiões administrativas com alta incidência que são Cruzeiro, Lago Norte, Plano Piloto, Varjão do Torto, Candagolândia, Estrutural, Guará, Núcleo Bandeirante, Park Way, Riacho Fundo II, SIA, Jardim Botânico, Itapoã, Lago Sul, Paranoá, São Sebastião, Fercal, Planaltina, Sobradinho I, Sobradinho II, Brazlândia, Ceilândia, Águas Claras, Recanto da Emas, Samambaia, Taguatinga, Vicente Pires, Gama, e Santa Maria. Os casos graves e óbitos até a Semana Epidemiológica de 2020, foramconfirmados 69 casos de dengue grave e 749 casos de dengue com sinais de alarme, com 44 óbitos, dez no Gama, quatro em Ceilândia e Planaltina, três em Samambaia e Vicente Pires, dois em Sobradinho, Guará, Sobradinho II, Lago Sul, Recanto das Emas, Taguatinga e Santa Maria, e um no Riacho Fundo II, Paranoá, 
Fercal, Águas Claras, Sudoeste-Octogonal e Plano Piloto. No mesmo momento do ano passado foram registrados 53 óbitos (Brasil, 2020).

A conscientização da população e do governo são necessárias, é um trabalho conjunto pois $90 \%$ dos focos do mosquito estão dentro dos domicílios, é necessário a verificação dos quintais, tampar tonéis, caixas d’água e qualquer outro tipo de recipiente que possa reservar água porque a dengue tem atacado muitas pessoas. A Vigilância Ambiental realiza um trabalho constante para realizar ações e inspeções de visita a locais com prováveis focos do mosquito Aedes aegypti. O subsecretário de Vigilância em Saúde do DF, Valero (2020) diz:

O problema da dengue hoje é um fenômeno mundial, ocorre em vários países, está ocorrendo, neste exato momento, em Minas Gerais, em Goiás, no entorno e aqui no DF. A única diferença é que, aqui no DF, nós estamos preparados para inverter esse quadro epidemiológico. Vamos fazer isso trabalhando e contando com a participação de todos (Valero, 2020).

A Secretaria de Saúde tem estruturado a hidratação nas unidades básicasde saúde (UBS), disponibilizando insumos para as modalidades oral e venosa, com isso pretende-se oferecer maior resolutividade e diminuir as complicações causadas pelo Aedes aegypti.

\section{Prevalência de Dengue nas regiões periféricas do Distrito Federal}

A deficiência em medidas de controle nas epidemias de dengue está ligada, segundo a capacidade de eliminação do vetor que se torna de extrema eficiência contra epidemias em áreas endêmicas. A disseminação do vetor é ampla entre latitudes $35^{\circ} \mathrm{N}$ e $35^{\text {a }} \mathrm{S}$, consideradas zonas intertropicais, se tratando do A. aegypty. No Brasil, em áreas endêmicas, tem-se em circulação os tipos DENV1, DENV2 (comagravamento em crianças e ocorrências de óbitos), DENV3 e propensão ao sorotipo DENV4 (Oms, 2012; Marzochi, 2004; Brasil, 2009).

Sobre a efetividade de um controle vetorial:

A Organização Pan-Americana da Saúde relatou que a interrupção da transmissão da dengue na Região das Américas resultou da campanha de erradicação do A. aegypti na região, realizada principalmente durante a década de 1960 e início da década de 1970. O monitoramento do vetor e as medidas de controle não tiveram continuidade e ocorreram ressurgências subsequentes do A. aegypti seguidas por surtos de dengue no Caribe e nas Américas Central e do Sul. Desde então, a dengue disseminou-se, com ocorrência de surtos a cada três a cinco anos (Oms, 2012).

Algumas determinantes sociais são favoráveis à prevalência de surtos epidemiológicos necessitando um olhar mais atento de órgãos governamentais, estaduais e municipais. A nossa constituição nos assegura que "A saúde é direito de todos e dever do Estado, garantido mediante políticas sociais e econômicas que visem à redução do risco de doença e de outros agravos e ao acesso universal e igualitário às ações e serviços para sua promoção, proteção e recuperação", assim, cabe aos responsáveis cumprir seu papel em conjunto com a sociedade (Valle et al., 2015; Brasil, 1990).

Em regiões endêmicas onde há o crescimento urbano descontrolado, resultando em falta de saneamento básico, mobilização em campanhas de conscientização, e ainda, terrenos baldios que são propensos à proliferação do vetorrequerem ações públicas e sociais de forma contínua. Sendo assim, as ações podem variar de uma região para outra de acordo com sua realidade e capacidade, sem abrir mão de dados que variam, mas se correlacionam: a infecção clínica, o vetor e a imunidade sorotípica da população a partir da coleta e monitoramento de dados por um sistema de vigilância eficiente e eficaz. Esse monitoramento pode determinar uma provável epidemia com indicação do vetor e mapeamento do padrão epidemiológico de determinada área (Marzochi, 2004). 
Dados os números de anos epidêmicos entre 2002 a 2017, foi possível mensurar espaços temporais das epidemias de dengue nas Regiões Administrativas (RAs) do DF com um total de 82 epidemias com 70.495 casos prováveis (Figura 1) representando 74\% em 2010, 2013, 2014 e 2016 (casos de zika ou chikungunya podem ter sido notificados como dengue por critério clínico epidemiológico e vice-versa). Esses dados evidenciam condições favoráveis para a reprodução do vetor e, consequentemente, para a transmissão e permanência da doença caracterizando-a como área endêmica, com notificação de casos o ano todo (Drumond et al., 2020).

Figura 1 - Distribuição espacial do número de epidemias por Região Administrativa do Distrito Federal (2007-2017)

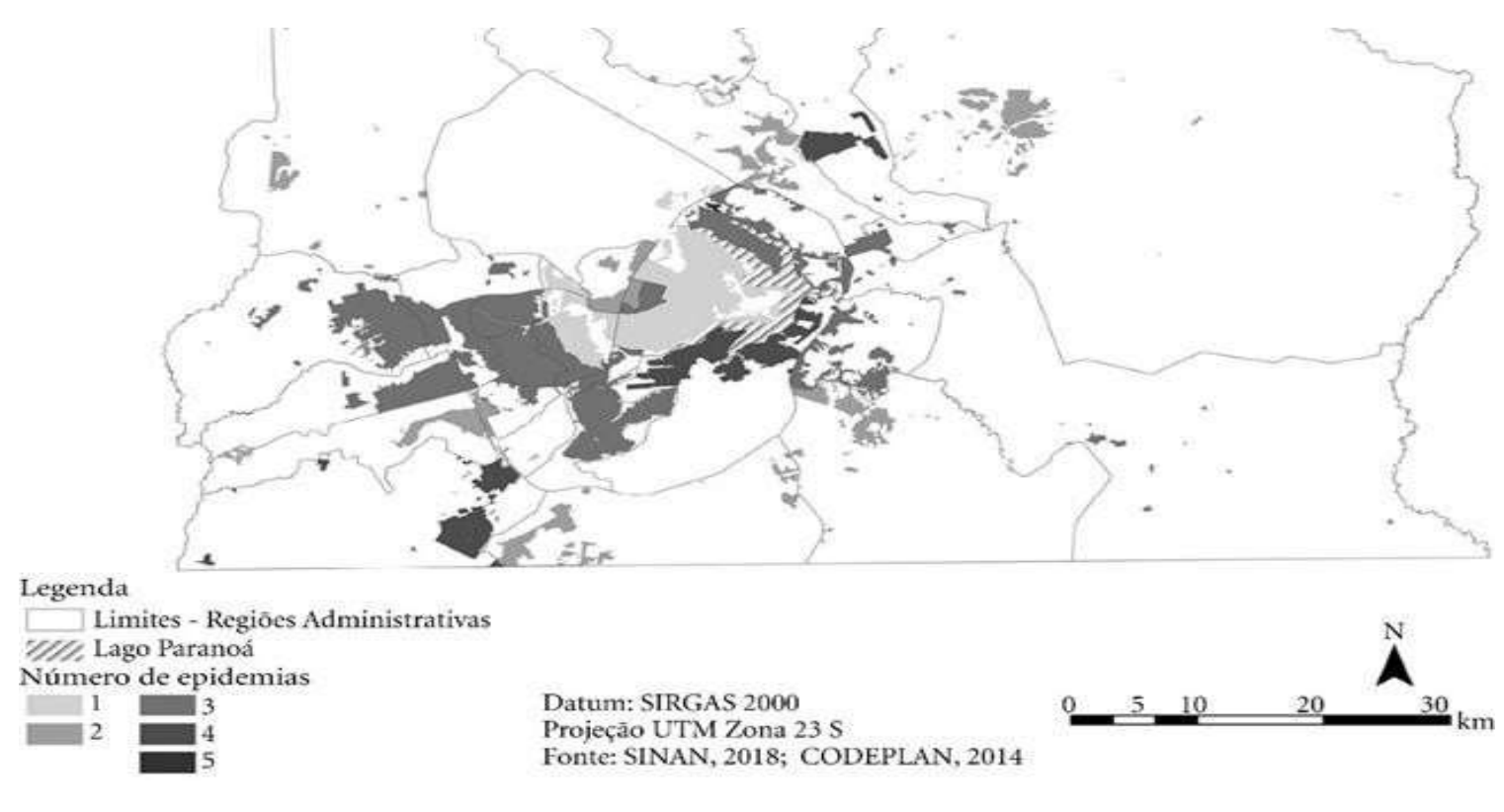

Fonte: SINAN (2018); CODEPLAN (2014).

No DF são circulantes os 4 sorotipos (Quadro 1) conferindo ao Distrito Federal hiperendemicidade. "A existência de muitos sorotipos circulando em uma grande população é um dos principais fatores da ocorrência contínua de epidemias ao longodos anos" (Barcellos, 2014; Drumond et al., 2020).

Em 2016 foram registrados 18 casos com 247 amostras até a SE 09 de 2016, sendo 57 nas seguintes RAs: Guará, dois casos; Santa Maria, dois casos; Gama, Riacho fundo e São Sebastião com um caso cada uma. Para DENV-3, um caso em Taguatinga e para DENV-4, três casos no total sendo Samambaia, Taguatinga e Ceilândia com um caso cada região admnistrativa. 
Quadro 1 -Monitoramento dos sorotipos de dengue circulantes no Distrito Federal, até a semana epidemiológica 09. DF, 2016.

\begin{tabular}{|c|c|c|c|c|c|}
\hline \multicolumn{2}{|c|}{$\mathrm{N}^{\circ}$ de amostras } & \multicolumn{4}{|c|}{ Sorotipos identificados } \\
\hline Analisadas & Isoladas & DENV1 & DENV2 & DENV3 & DENV4 \\
\hline 247 & 57 & 35 & 18 & 1 & 3 \\
\hline
\end{tabular}

Fonte: Trakcare/SES/DF (2016).

A Secretaria de Estado de Saúde (SES) registrou 3.932 casos suspeitos dedengue, até a semana epidemiológica (SE) 52 de 2018, dos quais 3.708 (94\%)(Tabela 1).

Tabela 1 - Casos de dengue no Distrito Federal por residência, até a semana epidemiológica 53.

Distrito Federal, 2017 e 2018.

\begin{tabular}{|c|c|c|c|c|c|c|c|}
\hline \multirow{2}{*}{$\begin{array}{l}\text { Casos de } \\
\text { dengue }\end{array}$} & \multicolumn{3}{|c|}{ Residentes no Distrito Federal } & \multicolumn{3}{|c|}{ Residentes em Outras UF's } & \multirow{2}{*}{$\begin{array}{c}\text { Total de } \\
\text { Casos } \\
2018\end{array}$} \\
\hline & 2017 & 2018 & $\begin{array}{r}\text { Variaçăo } \\
\% \\
\end{array}$ & 2017 & 2018 & $\begin{array}{r}\text { Variaçăo } \\
\% \\
\end{array}$ & \\
\hline Notificados & 6.035 & 3.708 & $-38,56$ & 770 & 224 & $.70,91$ & 3.932 \\
\hline Prováveis" & 3.971 & 2.351 & $-40,80$ & 549 & 112 & $-79,60$ & 2.463 \\
\hline
\end{tabular}

Fonte: SINAN Online, Dados atualizados em 03/01/2019 (da SE 1 a 52 de 2017 e 2018).

Por Regiões administrativas (Tabela 2): 
Tabela 2 - Distribuição dos casos prováveis de dengue em residentes, por Região de Saúde, até a semana epidemiológica 52. Distrito Federal, 2017 e 2018.

\begin{tabular}{|c|c|c|c|}
\hline \multirow{2}{*}{ Regiāo de Saúde } & \multicolumn{2}{|c|}{ casos de vengue } & \multirow{2}{*}{ Variaçäo\% } \\
\hline & 2017 & 2018 & \\
\hline Central & 103 & 59 & $-42,72$ \\
\hline -Asa Norte & 30 & 20 & $-33,33$ \\
\hline -Asa Sul & 31 & 6 & $-80,65$ \\
\hline -Cruzeiro & 6 & 8 & 33,33 \\
\hline - Lago Norte & 7 & 12 & 71,43 \\
\hline -Lago Sul & 16 & 9 & $-43,75$ \\
\hline -Sudoeste/Oct & 3 & 2 & $-33,33$ \\
\hline - Variala do Torto & 4 & 3 & $-25,00$ \\
\hline Centro-Sul & 452 & 123 & $-72,79$ \\
\hline -Candangolândia & 11 & 9 & $-18,18$ \\
\hline - Guará & 139 & 39 & $-71,94$ \\
\hline -Núcleo Bandeirante & 12 & 7 & $-41,67$ \\
\hline -Park Way & 10 & 3 & $-70,00$ \\
\hline -Riacho Fundo I & 55 & 21 & $-61,82$ \\
\hline -Riacho Fundo II & 68 & 20 & $-70,59$ \\
\hline -SCIA (Estrutural) & 156 & 23 & $-85,26$ \\
\hline SIA & 1 & 1 & 0,00 \\
\hline Leste & 551 & 575 & 4,36 \\
\hline -Itapoa & 115 & 116 & 0,87 \\
\hline Jardim Botânico & 9 & 6 & $-33,33$ \\
\hline -Paranoá & 127 & 154 & 21,26 \\
\hline - Săo Sebastialo & 300 & 299 & -0.33 \\
\hline Norte & 810 & 524 & $-35,31$ \\
\hline -Fercal & 27 & 7 & $-74,07$ \\
\hline -Planaltina & 553 & 426 & $-22,97$ \\
\hline $\begin{array}{l}\text {-Sobradinho } \\
\text {-Sobradinho II }\end{array}$ & $\begin{array}{l}119 \\
111\end{array}$ & $\begin{array}{l}52 \\
39\end{array}$ & $\begin{array}{l}-56.30 \\
-64,86\end{array}$ \\
\hline Oeste & 623 & 171 & -72.55 \\
\hline - Brazlândia & $\begin{array}{r}93 \\
530\end{array}$ & $\begin{array}{r}48 \\
123\end{array}$ & $\begin{array}{l}-48,39 \\
-76,79\end{array}$ \\
\hline Sudoeste & 818 & $\frac{120}{554}$ & $\frac{-70,15}{-32,27}$ \\
\hline -Aguas Claras & 59 & 31 & $-47,46$ \\
\hline -Recanto das Emas & 144 & 110 & $-23,61$ \\
\hline - Samambaia & 300 & 252 & $-16,00$ \\
\hline -Taguatinga & 277 & 127 & $-54,15$ \\
\hline - Vicente Pires & 38 & 34 & $-10,53$ \\
\hline Sul & 590 & 79 & -86.61 \\
\hline -Gama & 315 & 46 & $-85,40$ \\
\hline -Santa Maria & 275 & 33 & $-88,00$ \\
\hline Em Branco & 6 & 9 & 50,00 \\
\hline Năo Classificados & 3 & 0 & $-100,00$ \\
\hline Total & 3.956 & 2.094 & $-47,07$ \\
\hline
\end{tabular}

Fonte SINAN Online. Dados atualizados em 03/01/2018.

Para o ano seguinte, segundo Saúde (2019):

Em 2019, até a SE 12 (30/12/2018 a 23/03/2019), foram registrados 273.193 casos prováveis de dengue no país, com uma incidência de 131,0 casos/100 mil hab. (Figura 1 e Tabela 1). No mesmo período de 2018, foram registrados 71.525 casos prováveis. [...] A análise da taxa de incidência de casos prováveis de dengue (número de casos/100 mil hab.) em 2019, até a SE 12, segundo regiões geográficas, evidencia que as regiões Centro-Oeste e Sudeste apresentam os maiores valores: 298,7 casos/100 mil hab. e 204,9 casos/100 mil hab.,(Tabela 3) respectivamente $[\ldots]$ 
Tabela 3 - Casos e óbitos confirmados por dengue até a Semana Epidemiológica 12, Brasil, 2018 e2019.

\begin{tabular}{|c|c|c|c|c|c|c|}
\hline \multirow{4}{*}{ Regiăo/Unidade da Federação } & \multicolumn{6}{|c|}{ Semanas Epidemiológicas 1 a 12} \\
\hline & \multicolumn{4}{|c|}{ Casos confirmados } & \multicolumn{2}{|c|}{ Óbitos confirmados } \\
\hline & \multicolumn{2}{|c|}{2018} & \multicolumn{2}{|c|}{2019} & \multirow[b]{2}{*}{2018} & \multirow[b]{2}{*}{2019} \\
\hline & $\begin{array}{l}\text { Dengue com } \\
\text { sinais de } \\
\text { alarme }\end{array}$ & Dengue grave & $\begin{array}{c}\text { Dengue com } \\
\text { sinais de } \\
\text { alarme }\end{array}$ & Dengue grave & & \\
\hline Centro-0este & 888 & 55 & 602 & 44 & 25 & 19 \\
\hline Mato Grosso do Sul & 4 & 0 & 34 & 7 & 0 & 4 \\
\hline Mato Grosso & 5 & 0 & 7 & 0 & 0 & 0 \\
\hline Goiás & $8 \pi$ & 54 & 479 & 33 & 26 & 9 \\
\hline Distrito Federal & 2 & 1 & 82 & 4 & 1 & 6 \\
\hline
\end{tabular}

Fonte: Sinan Online (banco de dados de 2018 atualizado em 21/01/2019; de 2019, em 25/03/2019).

Por regiões administrativas (Tabela 4 e 5):

Tabela 4 - Incidência de casos prováveis de dengue, até a semana epidemiológica 35, por mês (calendário), por residência em região de saúde e regiões administrativas, no Distrito Federal, 2019.

\begin{tabular}{|c|c|c|c|c|c|c|c|c|c|}
\hline \multirow{2}{*}{ Regiăo de Saúde } & \multicolumn{8}{|c|}{ Incidência Mensal } & \multirow{2}{*}{$\begin{array}{c}\text { Incidêncla acumulada } \\
\text { (/100 mil hab.) }\end{array}$} \\
\hline & jan & fev & mar & $a b r$ & mai & jun & jul & ago & \\
\hline Central & 26,34 & 30,95 & 70,90 & 149,04 & 268,45 & 150,36 & 21,07 & 4,61 & 721,95 \\
\hline Asa Norte & 19,80 & 21,12 & 56,76 & 98,99 & 176,21 & 120,77 & 25,08 & 3,96 & 523,35 \\
\hline Asa Sul & 36,53 & 42,01 & 57,54 & 169,88 & 241,12 & 124,21 & 15,53 & 1,83 & 688,64 \\
\hline Cruzeiro & 23,14 & 34,71 & 92,55 & 141,14 & 152,70 & 120,31 & 16,20 & 2,31 & 583,05 \\
\hline Lago Norte & 19,60 & 34,29 & 90,64 & 178,82 & 404,18 & 215,56 & 26,95 & 7,35 & 977,39 \\
\hline Lago Sul & 47,11 & 44,49 & 73,29 & 78,52 & 212,00 & 136,10 & 13,09 & 7,85 & 612,45 \\
\hline Sudoeste/Octogonal & 14,65 & 14,65 & 43,95 & 70,00 & 110,69 & 48,83 & 11,39 & 3,26 & 317,42 \\
\hline Varjāo do Torto & 45,98 & 73,56 & 386,21 & $1.250,57$ & $2.868,97$ & 1324,14 & 101,15 & 36,78 & $6.087,36$ \\
\hline Centro-Sul & 33,42 & 72,02 & 184,75 & 317,23 & 478,58 & 305,38 & 39,81 & 14,28 & $1.446,38$ \\
\hline . Candangolândia & 46,65 & 67,39 & 212,53 & 549,48 & 668,71 & 305,84 & 31,10 & 5,18 & $1.886,89$ \\
\hline Guará & 24,15 & 42,27 & 135,11 & 270,22 & 502,70 & 332,87 & 40,76 & 8,30 & $1.357,89$ \\
\hline Núcleo Bandeirante & 50,02 & 140,07 & 413,53 & 513,57 & 573,60 & 223,44 & 33,35 & 20,01 & $1.970,92$ \\
\hline Park Way & 0,00 & 54,30 & 146,20 & 242,27 & 413,53 & 238,10 & 8,35 & 4,18 & $1.106,93$ \\
\hline Riacho Fundo I & 37,06 & 39,38 & 162,15 & 523,52 & 678,73 & 511,94 & 78,76 & 34,75 & $2.066,30$ \\
\hline . Riacho Fundo II & 4,71 & 40,08 & 54,22 & 155,59 & 266,40 & 223,96 & 40,08 & 25,93 & 810,98 \\
\hline Cid. Estrutural & 103,18 & 226,41 & 389,77 & 217,81 & 289,46 & 177,69 & 22,93 & 5,73 & $1.432,99$ \\
\hline S.I.A & - & - & - & - & - & 102,88 & - & - & 171,47 \\
\hline Leste & 181,71 & 399,43 & 584,45 & 599,35 & 994,23 & 634,12 & 72,44 & 18,21 & $3.483,94$ \\
\hline . Itapoã & 93,80 & 325,44 & 892,09 & 943.78 & 1510,42 & 790,63 & 67,00 & 19,14 & $4.642,30$ \\
\hline . Jardim Botânico & 61,79 & 102,99 & 90,63 & 123,58 & 362,51 & 86,51 & 16,48 & 4,12 & 848,61 \\
\hline Paranoá & 102,43 & 230,85 & 769,00 & $1.025,84$ & 1486,01 & 756,77 & 74,91 & 13,76 & $4.459,56$ \\
\hline Sāo Sebastiāo & 309,01 & 621,04 & 422,39 & 254,84 & 554,82 & 604,98 & 87,29 & 24,08 & $2.878,44$ \\
\hline Norte & 42,04 & 146,87 & 350,97 & 515,57 & 805,52 & 419,09 & 53,94 & 31,15 & $2.365,40$ \\
\hline Fercal & 66,68 & 85,73 & 800,15 & 523,91 & 1543,15 & 943,04 & 133,36 & 123,83 & $4.219,85$ \\
\hline Planaltina & 59,50 & 211,44 & 449,93 & & & 354,04 & 54,09 & 18,19 & $2.517,15$ \\
\hline Sobradinho & 26,66 & 72,52 & 137,57 & 311,39 & 668,64 & 404,17 & 49,05 & 25,59 & $1.696,65$ \\
\hline Sobradinho II & 14,90 & 83,65 & 295,65 & 462,96 & 1021,03 & 523,69 & 49,28 & 56,15 & $2.507,31$ \\
\hline Oeste & 26,01 & 55,66 & 98,95 & 213,53 & 350,31 & 182,43 & 34,74 & 10,91 & 972,54 \\
\hline Brazlândia & 94,74 & 233,22 & 201,15 & 311,93 & 491,21 & 505,79 & 32,07 & 1,46 & $1.871,56$ \\
\hline Ceilândia & 16,21 & 30,34 & 84,37 & 199,50 & 330,22 & 136,33 & 35,12 & 12,26 & 844,36 \\
\hline Sudoeste & 18,85 & 46,28 & 113,48 & 179,22 & 287,74 & 182,24 & 55,23 & 11,72 & 894,7 \\
\hline Águas Claras & 13,03 & 32,58 & 44,80 & 107,53 & 212,61 & 171,06 & 36,66 & 8,96 & 627,23 \\
\hline Recanto das Emas & 40,07 & 101,18 & 260,76 & 327,31 & 390,47 & 178,60 & 33,27 & 12,90 & $1.344,56$ \\
\hline Samambaia & 15,65 & 28,75 & 99,79 & 163,64 & 315,87 & 211,00 & 84,57 & 12,26 & 931,53 \\
\hline Taguatinga & 14,00 & 33,60 & 80,79 & 144,39 & 239,18 & 141,99 & 50,40 & 12,00 & 716,3 \\
\hline Vicente Pires & 12,68 & 59,19 & 87,38 & 170,54 & 281,88 & 255,10 & 52,15 & 11,28 & 930,2 \\
\hline Sul & 9,58 & 17,50 & 50,20 & 99,08 & 212,37 & 152,59 & 44,59 & 11,23 & 597,15 \\
\hline Gama & 6,75 & 10,43 & 33,14 & 83,47 & 208,05 & 148,52 & 42,96 & 12,89 & 546,22 \\
\hline Santa Maria & 12,87 & 25,75 & 70,08 & 117,28 & 217,40 & 157,33 & 46,48 & 9,30 & 656,5 \\
\hline Total & 38,82 & 87,55 & 181,19 & 269,54 & 444,66 & 258,51 & 46,18 & 13,80 & 1340,50 \\
\hline
\end{tabular}

Fonte: SINAN Online, 2019; FormSus (atualizado em 03/09/2019). Dados sujeitos à alteração. Houve 1204 casos prováveis sem a informação do endereçode residência e 02 não classificado. 
Tabela 5 - Número de casos prováveis e taxa de incidência de dengue (por 100 mil hab.), até a semana epidemiológica 51, segundo região de saúde e regiões administrativas. Distrito Federal, 2020.

\begin{tabular}{|c|c|c|}
\hline Região de Saúde & Casos de dengue & Taxa de incidência (/100 mil hab.) \\
\hline CENTRAL & 3.172 & 875,33 \\
\hline Cruzeiro & 359 & $1.163,54$ \\
\hline Lago Norte & 511 & $1.376,36$ \\
\hline Plano Piloto & 1.999 & 867,96 \\
\hline Sudoeste/Oct & 178 & 322,13 \\
\hline Varjão do Torto & 125 & $1.415,79$ \\
\hline CENTRO-SUL & 4.884 & $1.282,57$ \\
\hline Candangolândia & 261 & $1.597,50$ \\
\hline Estrutural & 235 & 639,11 \\
\hline . Guará & 2.868 & $2.040,41$ \\
\hline Núcleo Bandeirante & 234 & 974,23 \\
\hline Park Way & 197 & 854,37 \\
\hline Riacho Fundo I & 557 & $1.271,25$ \\
\hline . Riacho Fundo II & 518 & 553,32 \\
\hline SIA & 14 & 534,15 \\
\hline LESTE & 4.899 & $1.424,61$ \\
\hline Jardim Botânico & 445 & 765,42 \\
\hline Itapoã & 567 & 875,72 \\
\hline Lago Sul & 454 & 607,85 \\
\hline . Paranoá & 653 & 874,28 \\
\hline - São Sebastião & 2.780 & $2.396,80$ \\
\hline NORTE & 8.089 & $2.278,55$ \\
\hline Fercal & 261 & $2.755,49$ \\
\hline Planaltina & 2.550 & $1.300,45$ \\
\hline Sobradinho & 2.535 & $3.562,14$ \\
\hline Sobradinho II & 2.743 & $3.503,95$ \\
\hline OESTE & 5.874 & $1.156,64$ \\
\hline Brazlândia & 644 & $1.005,83$ \\
\hline Ceilândia & 5.230 & $1.178,40$ \\
\hline SUDOESTE & 11.747 & $1.415,86$ \\
\hline Águas Claras & 1.169 & 685,08 \\
\hline Recanto das Emas & 1.378 & $1.040,42$ \\
\hline Samambaia & 3.774 & $1.540,66$ \\
\hline . Taguatinga & 3.474 & $1.668,77$ \\
\hline . Vicente Pires & 1.952 & $2.657,52$ \\
\hline SUL & 8.522 & $3.122,08$ \\
\hline . Gama & 4.722 & $3.286,29$ \\
\hline . Santa Maria & 3.800 & $2.939,56$ \\
\hline Total & 47.422 & $1.553,52$ \\
\hline
\end{tabular}

Fonte: Sinan On-line. Dados atualizados em 16/11/2020 e 28/12/2020 respectivamente (da SE 01 a 51 de 2019 e 2020).

\section{Aumento no número de casos, descaso governamental ou populacional?}

É evidente o aumento do número significativo de casos de dengue entre os períodos de 2018 até o momento atual. Em 2018, foram confirmados 3.932. Atualmente em Novembro de 2020 foram notificados 46.145 casos prováveis de dengue (taxa de incidência de casos por 100 mil habitantes), sabe-se que o DistritoFederal em si está com alta incidência (Brasil, 2018; Brasil, 2020). 
Quem culpar diante crescente número de casos no Distrito Federal? População pela desinformação ou o governo? Já que as políticas de saúde e as ações de combate da dengue são pautadas somente no controle vetorial, menosprezando as atividades de educação em saúde (Reis, Andrade \& Cunha, 2013). A população tem sua parcela de culpa, entre os anos de 2015 a 2018 profissionais da saúde e estudantes do Distrito Federal realizaram ações educativas em diversas cidades, principalmente as que hoje possuem um número elevado de casos de Dengue, onde foram realizadas 24 ações educativas adaptadas a necessidade de cada público, foi apresentado uma escultura de gigante do mosquito, apresentações de teatro, textos, palestras e visitas domiciliares (Chaves, Evangelista \& Fernandes, 2020).

Ocorreu as trocas de governo entre 2018 e 2020, e o plano governamental continua o mesmo em combater somente o vetor e com pouco sucesso devido à precariedade de vivenda e de saneamento em diversas áreas e pelo grande nível pluviométrico as regiões, e com o estouro da pandemia de Covid-19, as ações ficaram mais limitadas (Lorenz et al., 2020; Wilder-Smith, 2020).

O número de notificações de dengue no Brasil até a semana epidemiológica (SE) 17 de 2020 ultrapassava o número de casos observados na SE 7 de 2015 e na SE 11 de 2019. Entretanto, a partir da SE 10 percebeu-se um declínio do número de notificações de dengue, coincidentemente no período em que as ações de saúde do país foram intensificadas para o combate da COVID-19, sugerindo uma possível subnotificação num período em que é esperado o aumento sazonal de casos de dengue no Brasil (MS, 2020).

Em 08 de Junho de 2020, foi lançado pelo Ministério da Saúde o novo plano de enfrentamento da Dengue e outras arboviroses (2020-2023), onde no plano a população atua junto com as ações governamentais visando a diminuição dos casos da doença e do controle vetorial, agora nos resta saber na prática no decorrer dos próximos anos (MS, 2020).

\section{Dengue em meio à pandemia}

Diante da situação da pandemia do novo coronavírus (Covid-19), os serviços da Brigada Estadual Itinerante de combate à dengue estão suspensos. A dengue em destaque foi uma das doenças que sofreu o afrouxamento do cuidado tanto da população como das políticas públicas de saúde. Visto as medidas de proteção adotadas contra a Covid-19, os programas de políticas públicas de saúde e de vigilância a dengue se ausentaram da população, não levando em consideração que o seu trabalho de combate não deve ser feito somente pela população, mas, também por eles. Devido esse afrouxamento o Brasil, em destaque o DF sofre um surto de dengue acompanhado do coronavírus, dando aos cidadãos a sensação de total vulnerabilidade (Funesa, 2020).

Mas segundo Gadelha (2020) "mesmo num cenário mais delicado, doenças como dengue, zika e chikungunya merecem igual atenção, pois todas são transmitidas por umúnico mosquito, que vem constantemente se adaptando a novas realidades em espaços urbanos".

A evolução nacional da dengue permite questionar severamente os pactos federativos de gestão escolhidos pelo SUS para controlar a epidemia. O Brasil andou na contramão da tendência mundial de decentralização da vigilância em saúde ao municipalizar as atividades operacionais nessa área. Ao contrário do senso comum que acha que o mosquito da dengue "Aedes aegypti" não tem dono, depois do Plano Nacional de Controle da Dengue (PNCD) ele tornou-se responsabilidade do município. O Ministério da Saúde reservou para si a parte nobrede formulação das políticas para o problema. A ampliação da participação das autoridades estaduais no controle da dengue é bem-vinda. A preocupação com a coordenação regional do controle da dengue e da própria atividade da vigilância em saúde deve voltar à agenda da política pública. A nova orientação produz uma inevitável apreensão (Costa, 2011). 


\section{Considerações Finais}

Em 2020 o país foi surpreendido com um novo vírus que expôs diversasdeficiências no suporte a promoção da saúde, o Sars-cov2. É evidente a forma com que o vírus se distribui, tendo em vista diversas determinantes sociais: econômicos, culturais, étnicos/raciais, psicológicos e comportamentais que influenciam todo evento de transmissão e aumento de casos. Esses fatores estão extremamente ligados a distribuição em grande escala da patologia causada pelo vírus Sars-cov2. Comportamentos que tem influenciado ocorrência de problemas de saúde e seus fatores de risco na população não é inerente apenas a Covid-19.

A Dengue tem sua endemicidade comprovada ao longo de várias epidemias, confirmando sua prevalência no Distrito Federal necessitando de ações educativas e promoção para prevenção contra a Dengue o Sars-cov2, em detrimento de ações no enfrentamento da dengue tem aumentado em 22,7\% os casos de dengue no Distrito Federal, comprovando o descontrole problemático devido ao enfrentamento ao Sars-cov-2. Porém, se observa que a imunidade sorotípica tem ocorrido ao longo dos anos de formas cíclicas demonstrando a falta de controle vetorial, apesar de um mapeamento ao longo dos anos, evidenciado um problema recorrente que merece mais atenção do governo e da população.

Esta pesquisa abre um leque para diversas outras pesquisas epidemiológicas no Distrito federal, sendo sugestiva a produção de trabalhos futuros que contribuam para esse mapeamento de risco e endemicidade.

\section{Referências}

Barcellos, C., \& Lowe, R. (2013). Expansion of the dengue transmission area in Brazil: the role of climate and cities. Tropical Medicine \& International Health, 19(2), 159-168. https://doi.org/10.1111/tmi.12227.

Boletim Epidemiológico, (2019). [s. l], 50(13), 1-12, abr. 2019. Anual. https://portalarquivos2.saude.gov.br/images/pdf/2019/abril/30/2019-013Monitoramento-dos- casos-de-arboviroses-urbanas-transmitidas-pelo-Aedes-publicacao.pdf.

Brasil. (1990). Lei Orgânica da Saúde. Dispõe sobre as condições para a promoção, proteção e recuperação da saúde, a organização eo funcionamento dos serviços correspondentes e dá outras providências. Diário Oficial da República Federativa do Brasil, 128(182).

Brasil. Ministério da Saúde, (2018). Secretaria de Vigilância em Saúde. Boletim EpidemiológicoAno 13 N 52. Dezembro 2018: 1-6.

Brasil. Ministério da Saúde, (2020). Secretaria de Vigilância em Saúde. Boletim EpidemiológicoAno 15 N 39. Novembro 2020 : 1-5.

Brasil, Ministério da Saúde, (2009). Secretaria de Vigilância em Saúde, \& Departamento de Vigilância Epidemiológica. Diretrizes nacionais para prevenção e controle de epidemias de dengue.

Chaves, M. D. O., Evangelista, M. D. S. N., \& Fernandes, F. M. D. C. (2020). Health education in Aedes aegypti: case study. Revista brasileira de enfermagem, 73.

Combate à Dengue durante o enfrentamento ao Coronavírus - FUNESA. (2020), March 16). Fundação Estadual de Saúde. https://www.funesa.se.gov.br/?page_id=604

Costa, N. D. R., Bellas, H., Silva, P. R. F. D., Carvalho, P. V. R. D., Uhr, D., Vieira, C., \& Jatobá, A. (2020). Agentes comunitários de saúde e a pandemia da Covid-19 nas favelas do Brasil.

De Oliveira, M. F. (2011). Metodologia científica: um manual para a realização de pesquisas em Administração. Universidade Federal de Goiás. Catalão-GO.

do Brasil, S. F. (1988). Constituição da república federativa do Brasil. Brasília: Senado Federal, Centro Gráfico.

Drumond, B., Ângelo, J., Xavier, D. R., Catão, R., Gurgel, H., \& Barcellos, C. (2020). Dinâmica espaço-temporal da dengue no Distrito Federal, Brasil: ocorrência e permanência de epidemias. Ciência \& Saúde Coletiva, 25(5), 1641-1652. https://doi.org/10.1590/1413-81232020255.32952019

Epidemiológicos, A. (2002). Dengue Diagnóstico e Tratamento. https://bvsms.saude.gov.br/bvs/publicacoes/dengue_aspecto_epidemiologicos_ diagnostico_tratamento.pdf

Federal, Secretaria de Saúde do Distrito. (Dez. 2018). Dengue, Chikungunya, Zika e Febre Amarela: dengue, chikungunya, zika e febre amarela. Informativo Epidemiológico, [s. $l], 13(52), 1-1$.

Federal, Secretaria de Saúde do Distrito. (2019). Comportamentoepidemiológicodas arboviroses, Distrito Federal, até a semana epidemiológica $\mathrm{n}^{\circ}$ 35, 2019: comportamento epidemiológico das arboviroses, distrito federal, até a semana epidemiológica $\mathrm{n}^{\text { }} 35$, 2019. Informativo Epidemiológico, [s.l], p.5-5. 
Federal, Secretaria de Saúde do Distrito. (Set. 2019). Informativo Epidemiológico: informativo epidemiológico. Informativo Epidemiológico, [s. l], 26(26), 55 .

Federal, Secretaria de Saúde do Distrito. (Mar 2016). Informativo Epidemiológico de Dengue, Chikungunya e Zika: informativo epidemiológico de dengue, chikungunya e zika. Informativo Epidemiológico, [s. l], 11(10), 5-5.

Federal, Secretaria de Saúde do Distrito. (Nov 2020). Monitoramento dos casos de dengue, Semanas Epidemiológicas 1 a 45 de 2020: boletim epidemiológico. Boletim Epidemiológico, [s. l], 15(39), 4-4.

Gadelha, J. (2020, September 3). Combate ao Aedes, durante a pandemia, é dever de todos. Fiocruz Rondônia. https://www.rondonia.fiocruz.br/combate-aoaedes-durante-a- pandemia-e-dever-de-todos/.

Lorenz, C., Azevedo, T. S., \& Chiaravalloti-Neto, F. (2020). COVID-19 and dengue fever: A dangerous combination for the health system in Brazil. Travel Medicine and Infectious Disease, 35, 101659. https://doi.org/10.1016/j.tmaid.2020.101659

Marzochi, K. B. F. (2004). Dengue endêmico: o desafio das estratégias de vigilância. Revista Da Sociedade Brasileira de Medicina Tropical, 37(5), 413-415. https://doi.org/10.1590/s0037-86822004000500009

Ministério da Saúde. (2020). Monitoramento dos casos de arboviroses urbanas transmitidas pelo Aedes aegypti (dengue, chikungunya e zika), Semanas Epidemiológicas 1 a 17, 2020. Bol Epidemiol; 51(18)

Ministério da Saúde. Secretaria de Estado de Saúde do Distrito Federal. (2020). Plano para enfrentamento da Dengue e outras arboviroses (2020-2023) Brasília.

Reis, C. B., Andrade, S. M. O. D., \& Cunha, R. V. D. (2013). Aliados do A. Aegypti: fatores contribuintes para a ocorrência do dengue segundo as representações sociais dos profissionais das equipes de saúde da família. Ciência \& Saúde Coletiva, 18, 517-526.

Santos, R. N. A., Duarte, G. A. B., Castanheira, L. S., Valiati, N. C. M., Dos Santos, N. C., \& Gitti, C. B. (2020, July). A importância da vigilância e prevenção de arboviroses em meio à pandemia de covid-19. In II Congresso de Saúde Coletiva da UFPR.

Saúde, O. P.-A. da. (2012). Primeiro relatório da OMS sobre doenças tropicais negligenciadas: Avanços para superar o impacto global de doenças tropicais negligenciadas. Organização Mundial Da Saúde. https://iris.paho.org/handle/10665.2/7680

Saúde, Ministério da. (2019). Monitoramento dos casos de arboviroses urbanas transmitidas pelo Aedes (dengue, chikungunya e Zika) até a Semana Epidemiológica 12 de 2019 e Levantamento Rápido de Indices para Aedes aegypti (LIRAa): monitoramento dos casos de arboviroses urbanas transmitidas pelo aedes (dengue, chikungunya e zika) até a semana epidemiológica 12 de 2019 e levantamento rápido de índices para aedes aegypti (liraa).

Secretaria de Saúde do Distrito Federal. (2020). Boletim Epidemiológico. Site. http://saude.df.gov.br/saude-divulga-boletim-epidemiologicosemanal-dadengue-2/.

Secretaria de Saúde do DIstrito Federal. (2020). Secretária de Saúde realiza nova açãode combate á dengue. Site. http://www.saude.df.gov.br/secretaria-desaude-realizou-nova-acao-de-combate-adengue

Valle, D., Pimenta, D. N., \& Cunha, R. V. da. (2015). Dengue: teorias e práticas. Editora Fiocruz. https://doi.org/10.7476/9788575415528

Wilder-Smith, A., Tissera, H., Ooi, E. E., Coloma, J., Scott, T. W., \& Gubler, D. J. (2020). Preventing dengue epidemics during the COVID-19 pandemic. The American journal of tropical medicine and hygiene, 103(2), 570. 